\title{
Pigmalionismo en la poesía del Bajo Barroco. Francisco Antonio de Castro tras las huellas de Loredano
}

\section{Pygmalionism in the Poetry of the Late Baroque. Francisco Antonio de Castro following in the Footsteps of Loredano}

\section{Miguel Carabias Orgaz}

Universidad de Salamanca

ESPAÑA

miguelcarabias@usal.es

[Hipogrifo, (issn: 2328-1308), 7.2, 2019, pp. 687-702]

Recibido: 02-01-2019 / Aceptado: 15-02-2019

DOI: http://dx.doi.org/10.13035/H.2019.07.02.49

Resumen. Ofrecemos la edición de un poema de Francisco Antonio de Castro, compuesto hacia comienzos del siglo XVIII, que se inspira en el episodio clásico de la Venus de Cnido y el sacrílego amante. El hecho de abordar el tema del pigmalionismo lo convierte en un caso singular dentro de la lírica española del Bajo Barroco. El texto, además, pone de manifiesto la influencia que tuvieron en Castro ciertas lecturas, concretamente las Bizzarrie accademiche de Giovan Francesco Loredano.

Palabras clave. Afrodita de Cnido; pigmalionismo; Francisco Antonio de Castro; Giovan Francesco Loredano; Bajo Barroco.

Abstract. We offer the edition of a text by Francisco Antonio de Castro, composed towards the beginning of the 18th century. It is inspired by the classic episode of Aphrodite of Cnidus and the sacrilegious lover. The fact of approaching the theme of Pygmalionism makes it a singular case in the Spanish lyric poetry of the Late Baroque. The text also highlights the influence that certain readings had on Castro, specifically Bizzarrie accademiche, by Giovan Francesco Loredano.

Keywords. Aphrodite of Knidos; Pygmalionism; Francisco Antonio de Castro; Giovan Francesco Loredano; Late Baroque. 
Recientemente daba a conocer la existencia de un cancionero, conservado en una sola copia manuscrita bajo el título Ocios líricos, que contiene gran parte de la producción del poeta alcalaíno Francisco Antonio de Castro (1670-1740). Este dejó inédita una obra abundante y variada en la que se compendian los principales temas y formas de la lírica barroca, aunque anticipando ya algunos aspectos que décadas más tarde señalarán el tránsito hacia una nueva sensibilidad literaria. Aunque no suele constar fecha explícita, las composiciones contenidas en Ocios líricos se pueden situar cronológicamente hacia la primera década del siglo XVIII'

En tanto voy concluyendo la edición del manuscrito, cuyo contenido se acerca a los ocho mil versos, quiero ofrecer en estas páginas un anticipo ciertamente singular: un poema que gira en torno a los amores sacrílegos de cierto ateniense con una estatua, que podemos identificar como la Afrodita de Cnido atribuida a Praxíteles. El episodio, recogido ya en algunas fuentes de la Antigüedad, despertará el interés de diversos escritores europeos desde el siglo XVI, pero fue rarísimo en la literatura española.

\section{PIGMALIONISMO Y LITERATURA. LA AFRODITA DE CNIDO}

Bajo los términos pigmalionismo o agalmatofilia se designa una anomalía sexual en que existe atracción por un cuerpo esculpido, el cual llega a producir las mismas reacciones que un cuerpo vivo². Desde la Antigüedad, numerosas fuentes se han referido al deseo amoroso que despertaron ciertas esculturas: además del conocido mito de Pigmalión, se pueden mencionar episodios presuntamente verídicos como los del Eros de Tespias, el Eros de Pario o la Afrodita Cnidia 3 .

Concretamente, lo sucedido en relación con la célebre Afrodita de Cnido suscitó el comentario de diversos autores. Aquella figura había sido esculpida por Praxíteles en el siglo IV a. C. - - se cree que el artista utilizó como modelo a su propia amante, la hetera o hetaira Friné ${ }^{-}$- y probablemente la hermosura de la estatua hizo que un muchacho se acabara enamorando de ella.

El suceso sería referido ya por el poeta griego Posidipo de Pela (c. 310-240 a. C.). Aunque no se conserva ese texto del autor, fue citado como fuente por Clemente de Alejandría 5 y por Arnobio:

Consimili ratione Posidippus in eo libro, quem scriptum super Cnido indicat superque rebus eius, adulescentem haud ignobilem memorat - sed vocabulum eius obscurat - corruptum amoribus Veneris, propter quam Cnidus in nomine est, amatorias et ipsum miscuisse lascivias cum eiusdem numinis signo genialibus usum toris et voluptatum consequentium finibus ${ }^{6}$.

1. Carabias Orgaz, 2018.

2. Para más detalles, pueden consultarse Olmos, 1992; Flynn, 2002, pp. 13-14; González García, 2006.

3. Gayo Plinio Segundo, Naturalis historia, XXXVI, 4, 22.

4. Alcifrón, Cartas de cortesanas, IV, «Friné a Praxíteles».

5. Clemente de Alejandría, Protréptico IV, 47 y 51.

6. Arnobio de Sicca, Adversus gentes VI, 22.4. 
En el siglo I, Valerio Máximo mencionaba aquel episodio, aunque muy brevemente, en sus Hechos y dichos memorables:

Volcanus... Cuius coniugem Praxiteles in marmore quasi spirantem in templo Cnidiorum collocavit, propter pulchritudinem operis a libidinoso cuiusdam conplexu parum tutam... ${ }^{7}$

Muchos más detalles ofrecía Plinio el Viejo en su Historia natural, explicando que Praxíteles hizo dos estatuas de Venus, una vestida y otra desnuda. En Cos adquirieron la primera, mientras que la imagen desnuda fue a parar a Cnido, donde alcanzó gran fama por su belleza. Cierto joven, llevado por una ciega atracción hacia la estatua, trató de poseerla sexualmente al amparo de la noche, dejando sobre ella la mancha que delataba su pasión:

... ante omnia est non solum Praxitelis, verum in toto orbe terrarum Venus, quam ut viderent, multi navigaverunt Cnidum. Duas fecerat simulque vendebat, alteram velata specie, quam ob id praetulerunt quorum condicio erat, Coi, cum eodem pretio detulisset, severum id ac pudicum arbitrantes; reiectam Cnidii emerunt, inmensa differentia famae.

Voluit eam a Cnidiis postea mercari rex Nicomedes, totum aes alienum, quod erat ingens, civitatis dissoluturum se promittens. Omnia perpeti maluere, nec inmerito; illo enim signo Praxiteles nobilitavit Cnidum. Aedicula eius tot aperitur, ut conspici possit undique effigies deae, favente ipsa, ut creditur, facta. Nec minor ex quacumque parte admiratio est. Ferunt amore captum quendam, cum delituisset noctu, simulacro cohaesisse, eiusque cupiditatis esse indicem maculam ${ }^{8}$.

Un relato similar, aunque con otros detalles, lo encontramos en Amores, el diálogo atribuido a Luciano de Samósata ${ }^{9}$, donde se describe el final desgraciado que tuvo su protagonista:

... sobre uno de los muslos vimos una mancha como la que queda sobre un vestido. Destacaba la fealdad en la superficie brillante del mármol [...] la diaconisa que se encontraba cerca de nosotros nos contó una extraña historia acerca de la increíble causa. Dijo que un joven de una familia distinguida -aunque, por lo sucedido, quedaba en el anonimato-, el cual acudía frecuentemente al templo, tuvo la mala suerte de enamorarse de la diosa, por lo que solía pasar allí el día entero [...] Finalmente, la tensión de su deseo fue desesperante e hizo de la audacia una alcahueta de su lascivia. Al caer el sol, sigilosamente se ocultó de los presentes tras una puerta y permaneció escondido en el interior del templo [...] ¿Para qué dar detalles de la desvergüenza ocurrida esa noche innombrable? La huella del erótico abrazo se descubrió la mañana siguiente y en la diosa quedó la mancha como prueba de lo sufrido. Aquel joven, según se dice en una popular leyenda, se

7. Valerio Máximo, Factorum et dictorum memorabilium, VIII, 11.

8. Gayo Plinio Segundo, Naturalis historia, XXXVI, 4, 20-21.

9. También en Los retratos, obra atribuida con certeza a Luciano, se hace referencia a este episodio. Luciano de Samósata, Los retratos, 4. 
arrojó desde un acantilado o bien se lanzó a las olas del mar para desaparecer totalmente... ${ }^{10}$

\section{AMORES SACRÍLEgOS EN LA LITERATURA BARROCA. GIOVAN FRANCESCO LOREDANO}

A partir del siglo XVI, y especialmente durante el periodo barroco, se recupera el interés por aquellos episodios sobre la atracción de algunos hombres hacia una estatua $^{11}$-con preferencia por el mito de Pigmalión-, que entre los escritores italianos tendrán amplia acogida ${ }^{12}$.

El caso concreto de la Afrodita de Praxíteles lo podemos encontrar mencionado ya en los Dicerie sacre de Giovan Battista Marino - «... la Venere di Prassitele e quella di Pigmalione, di cui s'innamorarono gli uomini» ${ }^{13}$-, aunque es en L'Adone donde este autor desarrolla el tema en sus detalles más físicos:
Sì viva è quell'effigie e sì spirante
che quasi ador ador si move e parla,
né vi passa romeo né navigante
che non rimanga stupido a mirarla;
e tal mirolla che furtivo amante
entrò di notte a stringerla e baciarla
e del lascivo ardor sfogato in essa
lasciò la macchia insu'l bel fianco impressa ${ }^{14}$.

Nos interesa especialmente la repercusión que alcanzó aquella historia del amante sacrílego en la obra del senador veneciano Giovan Francesco Loredano (1607-1661), quien se refería a ella en sus Scherzi ${ }^{15}$ y la recogió luego en sus Bizzarrie accademiche ${ }^{16}$. Escritor ingenioso y provocador, sombrío y extravagante, Loredano había sabido reunir un importante grupo de eruditos, artistas e intelectuales de diverso tipo, refundando e impulsando la Accademia degli Incogniti17. Su obra gozó de gran éxito y de una enorme difusión, pues él mismo logró catalizar gran parte de la actividad editorial en Venecia, sobre todo en colaboración con el impresor Giacomo Sarzina ${ }^{18}$. Como muchos de los incogniti, al amparo de la libertad que le ofrecía la república veneciana, lejos de la amenaza censora del papado, se

\footnotetext{
10. Pseudo-Luciano, Amores, 15-16.

11. Ver, al respecto, Bettini, 1992; Hinz, 1998; Stoichita, 2006; van Gasel, 2013; Munari, 2018.

12. Conrieri, 2003; Simone, 2016.

13. Marino, Dicerie sacre, p. 70.

14. Marino, L'Adone, XVI, 57.

15. Concretamente, en un breve texto bajo el título «Friné Lasciva». Loredano, Opere, pp. 149-163.

16. Loredano, Bizzarrie academiche, pp. 26-34

17. Recordemos que, junto con la actividad literaria, en la Accademia se promocionaron también otras artes como la pintura o la música, particularmente el teatro musical, con la fundación de un teatro propio, el Teatro Novissimo. Rosand, 1991

18. Es significativo que hayan podido localizarse casi trescientas ediciones de sus obras. Menegatti, 2000.
} 
relacionó con el pensamiento libertino del siglo XVII y algunos de sus textos fueron tildados de inmorales ${ }^{19}$.

Las Bizzarrie accademiche, conjunto de discursos concebidos para la Accademia, constituyen una sucesión de viñetas extravagantes e irónicas, principalmente sobre los temas del amor, las mujeres y el deseo. De tono satírico y abundantes en dobles sentidos, se concibieron pensando en una audiencia concreta y destacan principalmente por su erudición ${ }^{20}$. Uno de los textos contenidos en estas Bizzarrie lleva por título «Gli amori sacrileghi» ${ }^{21}$ y se presenta como un alegato de cierto ateniense ante el «Senato», donde trata de defenderse de una acusación de sacrilegio por haber amado lascivamente a la estatua de Venus. Aunque no llega a decirse expresamente, es indudable que se trata de la Afrodita de Cnido, pues Praxíteles aparece mencionado como autor de la misma.

La fuente principal de Loredano parece ser el Erotes atribuido a Luciano, aunque seguramente también tuvo presentes otros textos, como el Adversus gentes de Arnobio ${ }^{22}$, e incluso algunos modernos, como la Silva de varia lección de Pedro Mexía:

... parece cosa imposible y no creedera lo que ahora diremos y escriben los historiadores por cuento muy verdadero. Era en la ciudad de Atenas un mancebo de honesto linaje y de buen caudal y conocido, el cual, como muchas veces viese una estatua de mármol que en Atenas había, en un lugar público, de excelente talle y hechura, contemplando mucho en la perfección de la obra, vino a aficionarse y cautivarse de ella, de manera que no se podía apartar del lugar donde estaba, abrazándola y mirándola, y todo el tiempo que no estaba allí con ella, estaba triste y lloroso. Llegó a tanto su desvergüenza, que entró en el Senado ateniense y, prometiendo gran suma de dinero por ello, les suplicó le hiciesen merced de aquella estatua para llevar y tener consigo. No pareció al Senado cosa digna de su autoridad hacerlo ni vender la estatua pública, y fue para él la más triste cosa del mundo, y fuése de allí a la estatua y, poniéndole corona de oro y otros vestidos y joyas muy ricas, la adoraba y contemplaba. $Y$ en este desatino perseveró muchos días hasta que, siéndole por los magistrados vedado el estar en presencia de su estatua, como él quería, finalmente, sin seso, inducido por el demonio, él se mató con sus manos ${ }^{23}$.

Es significativo que, a diferencia de las fuentes clásicas, tanto Mexía como Loredano sitúen los hechos en Atenas, sin mencionar siquiera Cnido, y hablen de un muchacho ateniense de buena familia que se somete al juicio de las autoridades de la ciudad. Además, Mexía lo compara con Jerjes, que se enamoró de un plátano, ejemplo utilizado también por Loredano. Todo esto lleva a pensar en otras fuentes comunes, distintas de las que hemos mencionado -Plinio, Luciano, etc.-. Tampoco hay que descartar que se tuviera a la vista, además, algún relato sobre el juicio de Friné en el Areópago ateniense, con la sorprendente defensa de Hiperides.

19. Miato, 1998; Morini, 1998.

20. Heller, 2003, pp. 52-53.

21. Loredano, Bizzarrie academiche, pp. 26-34.

22. Simone, 2016

23. Mexía, Silva de varia lección, III, 14. 
Loredano añade, como dato novedoso, el nombre del sacrílego: Amicleo. Ignoramos de dónde pudo tomarlo, aunque podría tener un valor simbólico, pues además de ser el nombre de un escultor griego del siglo $\vee$ a. C. - que no dejaría de resultar irónico, tratándose de amores con una escultura-, fue también epíteto de Apolo, dios de la poesía, la belleza y las artes. Aunque el aspecto más original de «Gli amori sacrileghi» es el hecho de simular un discurso en primera persona, puesto en boca del protagonista, apoyándose en argumentos que evidencian aquella ambigüedad moral tan característica de los incogniti.

De hecho, es interesante comprobar que este discurso de Loredano tuvo una inmediata repercusión literaria, seguramente por su dudosa moralidad, la cual despertaría no pocos recelos. Así, encontramos un texto que guarda estrecha relación con el de las Bizzarrie, bajo el título «Al Senato Atheniese», sin duda concebido como réplica al de Loredano e incluido en La secretaria di Apollo de Antonio Santa $\mathrm{Croce}^{24}$. Se presenta como una sentencia dictada por Apolo en el caso de Amicleo: «Comanda Sua Maestà I'assoluzione di Amicleo, benche convinto del suo amore sacrilego». Describe el episodio como un «nuovo e non più udito amore» que ha causado gran maravilla en el Parnaso, por lo que «molti giorni tutte le lingue sono state impiegate in tal discorso», calificándose los hechos de «sacrilegio», «peccato», «nefande sue dissolutezze». Apolo decide dar una sentencia cruel: no ordena dar muerte a Amicleo, sino concederle la estatua ya profanada e indigna de adoración para que siga amándola sin ser correspondido y sin esperanza alguna.

\section{FRANCISCO ANTONIO DE CASTRO TRAS LAS HUELLAS DE LOREDANO}

En la literatura española, el episodio que estudiamos es sumamente raro y solo se aborda de forma indirecta ${ }^{25}$. Pedro Mexía, como acabamos de ver, en su Silva de varia lección menciona la locura amorosa suscitada por una estatua que puede identificarse con la de Cnido, aunque no se llega a nombrar explícitamente y se omiten detalles lascivos. También se alude a ello en los Discursos apologéticos de Juan de Butrón, muy brevemente ${ }^{26}$. La repercusión en la lírica casi podría limitarse a Quevedo, quien dedicó un soneto al asunto de Friné y la estatua ${ }^{27}$.

La causa de tal escasez de ejemplos podría tener su explicación en la autocensura que se impusieron los autores españoles ante determinados temas, como los que podían hacerlos sospechosos de libertinaje ${ }^{28}$. Y tal vez sea este también el motivo por el que Francisco Antonio de Castro no llegó a publicar la composición que

24. Santa Croce, La secretaria di Apollo, pp. 48-49. Esta se presentaba como continuación de la célebre obra de Traiano Boccalini (1556-1613): «La secretaria di Apollo, che segue gli Ragguagli di Parnaso del Boccalini». Aunque en la primera edición no figura el autor, en las posteriores ya sí consta el nombre de Santa Croce.

25. Algo más utilizado, sin ser frecuente, es el mito de Pigmalión en la literatura española del Siglo de Oro. Pueden verse al respecto Cristóbal, 2003; Rubio Árquez y Sáez, 2017.

26. Butrón, Discursos apologéticos, fol. 83v.

27. Quevedo, El Parnaso español, «Polimnia», LXXVIII. Puede verse, en relación con este poema, Nider, 2017.

28. Nider, 2017 
aquí presentamos, al igual que sucedió con otras suyas, que podían considerarse escandalosas y que seguramente reservaba, manuscritas, para el ámbito privado.

Si Castro abordaba en uno de sus poemas el episodio de la Cnidia y los amores sacrílegos, fue sin duda bajo la influencia de sus lecturas italianas y, concretamente, tras las huellas de Giovan Francesco Loredano. La influencia literaria italiana en España, que había sido ya importante durante los Siglos de Oro $^{29}$, no lo fue menos durante el Bajo Barroco, concretamente en la primera mitad del siglo XVIII, cuando la nueva dinastía reinante favoreció la introducción de gustos y modas procedentes de Italia.

Loredano, al igual que los demás incogniti y otros autores italianos del Seiscientos $^{30}$, fue leído e imitado, y se tradujo su obra al español desde la segunda mitad del siglo XVII, aunque con ciertas limitaciones: además de alguna obra de carácter didáctico o erudito ${ }^{31}$, interesan las traducciones de L'Adamo -con modificaciones sustanciales con respecto al original ${ }^{32}$ - y de la Vita del cavalier Marino ${ }^{33}$. Sus Scherzi vieron dos traducciones diferentes en pocos años: la de la primera parte se publicó en 1688; la de ambas partes, en 1731, con un prólogo de Mayans y Siscar, aunque su traductor, Egual, omitió dos de los scherzi por considerarlos poco decentes ${ }^{34}$.

Las colecciones de discursos ficticios de personajes clásicos constituyeron un género de la oratoria profana desarrollado en italiano desde la primera mitad del siglo XVII, principalmente a partir de I furori della gioventù de Giovanni Battista Manzini y los Scherzi geniali de Loredano. Asímismo, alcanzaron una notable repercusión en la literatura española, pues ya en el mismo siglo XVII algunos de estos discursos fueron traducidos o imitados. Ejemplo paradigmático sería el de las Ideas posibles (1692) de José Penso, donde se insertan cinco discursos de autores italianos de la Accademia degli Incogniti, incluido Loredano, quien ejerció una fuerte influencia en este autor judeoespañol35.

En Francisco Antonio de Castro la influencia italiana debió de ser también importante, como acabamos de apuntar. Por un lado, son frecuentes en su obra las alusiones a usos, costumbres y modas de origen italiano. Así, uno de los poemas más interesantes de nuestro autor gira en torno a un «juglar trufaldín» que, «con eco italiano», en «el teatro del mundo», «juguetes inventa para divertir», en evidente alusión a los Trufaldines, una compañía italiana de commedia dell'arte que llegó a

29. Para el periodo barroco, ver los trabajos ya clásicos de Chevalier, 1966 y Arce, 1973. También pueden ser útiles, para una visión de conjunto, Seco, 1990 y Cacho Casal, 2003.

30. Ver al respecto Nider, 2011; Vuelta García, 2011

31. Loredano, Vida de Alexandro Tercero, pontífice máximo.

32. Conrieri, 2006 y 2011

33. Encontramos una copia manuscrita del siglo XVIII en la Biblioteca Nacional de España, bajo la signatura Ms. 8601.

34. Loredano, Burlas de la fortuna en afectos retóricos de el Loredano; Loredano, Declamaciones geniales.. 35. De hecho, además del discurso que toma de los Scherzi, Penso afirmaba en el prólogo de Rumbos peligrosos haber traducido los «Psalmos Penitenciales» y la «Vida de Adán» de Loredano, y se inspiraría en un texto contenido en las Bizzarrie para redactar su panegírico sacro a La Rosa. Nider, 2010. 
la corte con el rey Felipe $\mathrm{V}^{36}$. Pero, sobre todo, interesa subrayar la incidencia de la literatura italiana en sus lecturas y en su labor intelectual, indicio de lo cual podemos considerar su traducción de una obra publicada por Giovanni Battista Comazzi $(1654-1711)^{37}$.

Por otro lado, un motivo tan habitual en la literatura barroca como fue el de la estatua, lo había introducido Castro también en otras composiciones suyas: el soneto «A una perfecta efigie de san Bruno» desarrolla la idea de que el arte puede superar la realidad; en otro texto, la vacuidad de la gente a la hora del paseo remite a la leyenda de Falerina - «... estatuas de Falerina / se tropiezan a millares, / que solo fundan el alma / en una almilla de encajes».

En este contexto se inscribe el poema que aquí editamos, inspirado sin duda en el discurso de las Bizzarrie que anteriormente mencionábamos. Se trata de un texto introducido por un extenso título, en consonancia con los usos literarios de la época: «Amicleo Ateniense, condenado a muerte por adorar lascivamente la estatua de Venus, impugna la acusación disculpando la ceguedad de su delito en este romance». Al igual que Loredano, Castro simula un alegato dirigido por el sacrílego al Areópago. También da el nombre de Amicleo y pone en su boca muchos de los argumentos falaces que hay en el texto de las Bizzarrie, como podemos comprobar en los siguientes ejemplos:

Amicleo se pregunta, sorprendido, por la aparente paradoja de que se castigue el saber amar, que él estima una virtud, y no se castigue a quien no sabe hacerlo.

Dunque solamente in Athene si castiga chi sà amare? O infelizità della nostra conditione, ò miserie del nostro secolo! II saper'amare, ch'è una qualità...

...m'imaginavo più facilmente d'esser chiamato reo per non haver saputo amare, che per haver amato.

\author{
¿Saber amar se castiga \\ en Atenas, donde debe \\ de amor la ignorancia, como \\ ignorancia, reprehenderse? \\ ¿Saber amar se castiga? \\ La misma razón se queje; \\ solo en amor es delito \\ ignorarle, no el saberle.
}

En un alarde de cinismo, el muchacho argumenta que, si alguien merece un castigo por el sacrilegio, es el escultor que ha creado una estatua de mármol reproduciendo la belleza de Venus.

36. Doménech, 2005. El poema de Castro al que aludo se puede leer en Carabias, 2018, pp. 146-147. Bien es cierto que, en ocasiones, Castro tiende a presentar lo italiano con un matiz negativo o peyorativo, como al referirse a cierto médico en una composición incluida en sus Ocios líricos: «Recetó de la cigüeña / la dura invasión nefanda, / bujarrón pasa adelante / con la receta italiana».

37. La traducción lleva por título La moral de príncipes observada en la historia de todos los emperadores que reinaron en Roma y quedó inédita. La única copia manuscrita que he podido localizar se encuentra en la Real Academia de la Historia, 9/2264. La obra original se publicó en Viena en 1689 con el título La morale dei principi osservata nell'Istoria di tutti gli imperatori che regnarono in Roma. 
... se merito castigo, lo merita prima di me Prasitele, che hà saputo far una statua, che etiandio di sasso incita alla libidine. Temerario artefice, che hai voluto, che la tue fittioni contendino con la verità; che le Veneri finte innamorino, como le vere; e che l'Arte imiti in tutte le cose la natura.

\author{
Muera solo quien osado \\ supo emular lo celeste \\ construyendo perfecciones \\ del hierro de los sinceles; \\ muera el artífice necio \\ que a lo infinito se atreve, \\ limitando a un mármol duro \\ celestiales rosicleres...
}

Finalmente, Amicleo solicita a quienes lo juzgan que, si algún castigo ha de recibir, sea el de continuar amando un mármol sin esperanza de ser correspondido.

... qual maggior castigo mi si può dare, che il lasciarmi continuare ad amarla? L'amare senza speranza d'esser riamato è il maggior castigo, che possa ricevere un'anima più che empia. Qual maggior pena può tormentare chi ama, che amare una Venere di marmo? Qual maggior punitione può ricevere un cuore, ch'esser costretto all'adoratione ed alla fruittione d'un falso!

Aunque, obviamente, Castro añadió ideas y argumentos propios, en general tiende a la abbreviatio con respecto a su modelo, prescindiendo de contenidos - ni siquiera menciona a Praxíteles, y tampoco utiliza los ejemplos de Alcetas Rhodius o Jerjes, por citar algunos-, seguramente con objeto de dinamizar el texto y adecuarlo a la forma versificada. Pese a ello, mantiene prácticamente la misma estructura que la del texto italiano. El poema se inicia con un apóstrofe al Areópago, Amicleo expone el motivo por el que lo juzgan (vv. 1-8). A continuación, el reo aduce una serie de razones con las que trata de persuadir de la inocencia de sus actos (vv. 9-104). Al final solicita que, en todo caso, su castigo sea el de continuar con vida, una condena peor que la muerte, pues de ese modo seguirá amando sin posibilidad de ser correspondido (vv. 105-148).

Nuestro autor opta en esta composición, como en otras muchas de sus Ocios líricos, por el romance como forma métrica ${ }^{38}$. En total, consta de 148 versos. Los octosílabos se caracterizan por su regularidad, apoyada ocasionalmente en la sinalefa y la sinéresis. Predominan los versos paroxítonos, con escasas excepciones de versos oxítonos. La rima es paroxítona.

En el plano estilístico, el ritmo del poema queda marcado por frecuentes paralelismos: destaca el uso de la anáfora, con algún ejemplo de quiasmo (vv. 27-28) y de anadiplosis (vv. 131-132). Como ya señalé de modo general para el conjunto de su producción lírica, en este texto Castro manifiesta una clara predilección por la antítesis y la paradoja (vv. 133-134), que delatan la continuidad de patrones esté-

38. Para el estudio de la pervivencia y adaptación del romance en la poesía del Bajo Barroco, pueden consultarse Di Stefano, 2011 y Ruiz Pérez, 2013 
ticos del periodo barroco. También a nivel semántico, encontramos algún vocablo que, dado el contexto temático, parece adquirir una connotación sexual -«Fino, mi ardor califica / de culto el ardor que vierte» (vv. 61-62)-. En conjunto, el autor se apoya en la ironía y llega a dar la impresión de cierto relativismo o ambigüedad: por un lado, se percibe una voluntad de burla; por otro lado, el texto podría interpretarse como manifestación de laxitud moral - «... a la deidad del halago / es respecto el no tenerle» (vv. 83-84)-, contemplando con indulgencia determinadas actitudes, como la exaltación del deseo amoroso para justificar cualquier comportamiento - «¿Por qué sacrílegos culpan / mis amantes procederes, / si en los votos del cariño / no hay holocausto indecente?» (vv. 93-96).

\section{TEXTO: CRITERIOS Y EDICIÓN}

El poema se encuentra recogido en el manuscrito único de Ocios líricos, folios 200r al 204r. Editamos el texto según los siguientes criterios:

- Hemos modernizado las grafías en todos aquellos aspectos que no suponen alteración de valores fonológicos.

- Se regularizan puntuación y acentuación según el uso actual.

- Se regulariza el uso de mayúsculas según la norma actual.

-Se reservan las notas a pie de página para las formas en desuso.

AMICLEO ATENIENSE, CONDENADO A MUERTE POR ADORAR LASCIVAMENTE LA ESTATUA DE VENUS, IMPUGNA LA ACUSACIÓN DISCULPANDO LA CEGUEDAD DE SU DELITO EN ESTE ROMANCE

\footnotetext{
Areópago sacro, cuyas

justas veneradas leyes

está temiendo el respecto ${ }^{1}$,

aun cuando las obedece;

reo de amor, mi delito

se ilustra al ver que se estrene

- cuando el no adorar es culpa-

que haya en amor delincuentes.

¿Saber amar se castiga

en Atenas, donde debe

de amor la ignorancia, como

ignorancia, reprehenderse?

¿Saber amar se castiga?

La misma razón se queje;

solo en amor es delito

ignorarle, no el saberle.
} 
Yo amé. Si mi culpa es esta,

la repito una y mil veces,

porque fuera mayor cargo

callar causa tan decente.

Yo adoré a un mármol, a cuyas

inmutables solideces

quiso fina mi constancia

emularles lo rebelde.

Yo amé. A este cargo, la ley

injusta es bien que deteste,

que hace al inocente reo,

siendo el reo el inocente.

Un mármol fue el dulce objeto

de mis suspiros ardientes,

$y$, aunque continuos, pudieron

solo animar sus desdenes;

advertid, ya que mi amor

de su dureza se infiere,

iqué amara correspondido

quien ama así a quien no siente!

$$
\text { ¿La perfección no es objeto }
$$

del amor? Pues al que atiende

perfecto un mármol, ¿por qué

se culpa que le venere?

Si es alma de amor, lo hermoso

lo insensible desvanece,

pues la perfección es alma

que su dureza desmiente;

nueva hermosura es la muda

firmeza que la mantiene,

para que aprendan constancias

las almas que se suspenden.

Si lo hermoso y lo inconstante

inseparables se advierten,

más que instables perfecciones

valen firmes esquiveces.

Mi suerte a adorar un mármol

me indujo dichosamente,

y es rigor el castigar

como delito una suerte.

Constante adoré rigores

sin aspirar a otros bienes,

que el que ama correspondencias

adora sus intereses. 
Fino, mi amor califica

de culto el ardor que vierte,

que amar en su estatua a Venus

es culto el más reverente;

si en su simulacro hermoso

es atractivo elocuente,

¿cómo ha de estar muda una alma

que de aquel aliento pende?

Cultos que la diosa aceta ${ }^{2}$

¿quién a culparlos se atreve,

si el mirar que los permite

prueba es de que no se ofende?

Si acusáis torpe el halago

como afecto irreverente,

siempre para Venus fueron

sacrificios los deleites.

No adorarla fuera cargo

más justo, pues, si se advierte,

mal ser puede el incentivo

rémora de los placeres.

El halagüeño holocausto

es su culto más solemne,

que a la deidad del halago

es respecto ${ }^{3}$ el no tenerle;

ni en su deidad ni en su estatua $\quad 85$

las inmunidades pierde,

pues, aun lográndose fácil,

estatua y deidad es siempre.

Si es madre de Amor la diosa,

y de su deidad procede,

¿cómo, a vista de la causa,

podrá el efecto esconderse?

¿Por qué sacrílegos culpan

mis amantes procederes,

si en los votos del cariño

no hay holocausto indecente?

No hay duda que admite grata

cultos que acusáis de aleves,

pues aun en su esquivo mármol

tratable se me concede.

Luego, es injusto el castigo

al ver que Venus tolere

como obsequio suyo el logro

que sacrilegio os parece. 
La vida os pido en castigo,

105

si mis razones os mueven,

pues para un amante fino

la vida es la mayor muerte.

Morir no puede ser pena

en quien como yo padece,

pues ya tienen fin dichoso

los tormentos en quien muere.

Muera solo quien osado

supo emular lo celeste,

construyendo perfecciones

del hierro 4 de los sinceles 5 ;

muera el artífice necio

que a lo infinito se atreve,

limitando a un mármol duro

celestiales rosicleres;

muera, pues que supo diestro

de un mármol la helada nieve

animarla en los incendios

que produce y que carece.

Con su destreza, mi error

110

disculpado es bien que quede,

pues si el que sigue un milagro

yerra, ¿quién habrá que acierte?

Resistirme a tal prodigio

fuera en mí el cargo más fuerte,

porque no fuera incentivo

incentivo que no vence.

Cúlpese solo su acierto,

pues que fue error evidente,

y queden solo mis yerros,

por amorosos, indemnes.

Además, que si al castigo

mayor queréis exponerme,

¿qué mayor que el que esté amando

un mármol continuamente?

Dejadme en mi pena amante

sin que otra mi culpa aqueje,

que el delito es su mayor

castigo al que lo comete.

4. En el manuscrito, la forma ierro. Probablemente se creaba una ambigüedad intencionada, que permitía un juego de palabras mediante la dilogía - hierro / yerro-, tan frecuentemente empleada por Castro. 5. sincel: lo mismo que cincel (Autoridades). 
Y pues en su estatua Venus

mis justas quejas atiende,

dejad que su eterno mármol

su eterno rigor me acuerde ${ }^{6}$.

\section{BiBLIOGRAFÍA}

Arce, Joaquín, Tasso y la poesía española. Repercusión literaria y confrontación lingüística, Barcelona, Planeta, 1973.

Bettini, Maurizio, Il ritratto dell'amante, Torino, Einaudi, 1992.

Butrón, Juan de, Discursos apologéticos en que se defiende la ingenuidad del arte de la pintura..., Madrid, Luis Sánchez, 1626.

Cacho Casal, Rodrigo, «La poesía burlesca del Siglo de Oro y sus modelos italianos», Nueva Revista de Filología Hispánica, 51.2, 2003, pp. 465-491.

Carabias Orgaz, Miguel, «Ocios líricos. La obra olvidada de Francisco Antonio de Castro (1670-1740)», Janus, 7, 2018, pp. 121-151.

Chevalier, Maxime, L'Arioste en Espagne (1530-1650): recherches sur l'influence du «Roland furieux», Bordeaux, Féret et fils, 1966.

Conrieri, Davide, «Postille all'Adone», Studi Secenteschi, 44, 2003, pp. 318-322.

Conrieri, Davide, «Antonio Vázquez traduttore dall'italiano allo spagnolo», Studi Secenteschi, 47, 2006, pp. 153-172.

Conrieri, Davide, «L'Adamo di Giovan Francesco Loredano nella Penisola Iberica», en Gli Incogniti e l'Europa, ed. Davide Conrieri, Bologna, I libri di Emil, 2011, pp. 77-124.

Cristóbal, Vicente, «Pigmalión y la estatua: muestras de un tema ovidiano en la poesía española», Cuadernos de Filología Clásica. Estudios Latinos, 23.1, 2003, pp. 63-87.

Di Stefano, Giuseppe, «El romance entre poetas, críticos y libros de poesía en los albores de la modernidad», Bulletin hispanique, 113.1, 2011, pp. 129-162.

Doménech Rico, Fernando, La compañía de los Trufaldines y el primer teatro de los Caños del peral, tesis doctoral, Madrid, Universidad Complutense de Madrid, 2005.

Flynn, Tom, El cuerpo en la escultura, Madrid, Akal, 2002.

González García, Juan Luis, «Por amor al arte. Notas sobre la agalmatofilia y la Imitatio Creatoris, de Platón a Winckelmann», Anales de Historia del Arte, 16, 2006, pp. 131-150. 
Heller, Wendy B., Emblems of Eloquence. Opera and Women's voices in Seventeenth-Century Venice, Berkeley, University of California, 2003.

Hinz, Berthold, Aphrodite: Geschichte einer abendländischen Passion, München, Hanser, 1998.

Loredano, Giovan Francesco, Bizzarrie academiche, Venezia, Giacomo Sarzina, 1638.

Loredano, Giovan Francesco, Burlas de la fortuna en afectos retóricos de el Loredano, trad. Eugenio de Miranda, Madrid, [s. i.], 1688.

Loredano, Giovan Francesco, Declamaciones geniales..., trad. Miguel Egual, Valencia, Antonio Bordazar, 1731.

Loredano, Giovan Francesco, Opere del Loredano, divise in sette volumi. Volume primo, Venezia, Guerigli, 1661.

Loredano, Giovan Francesco, Vida de Alexandro Tercero, pontífice máximo, trad. Antonio Velázquez, Madrid, Gregorio Rodríguez, 1657.

Marino, Giovan Battista, Dicerie sacre, ed. Erminia Ardissino, Roma, Edizioni di Storia e Letteratura, 2014.

Menegatti, Tiziana, Ex ignoto notus. Bibliografia delle opere a stampa del Principe degli Incogniti: Giovan Francesco Loredano, Padova, II Poligrafo, 2000.

Mexía, Pedro, Silva de varia lección, Valladolid, Juan de Villaquirán, 1551.

Miato, Monica: L'Accademia degli Incogniti di Giovan Francesco Loredan, Venezia (1630-1661), Firenze, Olschki, 1998.

Morini, Agnès, «Giovan Francesco Loredan (1606-1661): le retour à la bergerie», en Soulèvements et ruptures: I'Italie en quête de sa Révolution. Echos littéraires et artistiques, ed. Bruno Toppan, Nancy, Université de Nancy, 1998, pp. 73-88.

Munari, Alessandra, «La statua animata: dalla Biblia al mito classico e ermetico, fino alla scena barocca», en La letteratura italiana e le arti. Atti del XX Congresso dell'ADI-Associazione degli Italianisti (Napoli, 7-10 settembre 2016), Roma, Associazione degli Italianisti, 2018, disponible en <http://www.italianisti.it/ upload/userfiles/files/5\%20Munari.pdf>.

Nider, Valentina, «José Penso e l'Accademia Sefardita "de los Sitibundos" di Livorno nella diffusione di un genere oratorio fra Italia e Spagna: Traduzione e imitazione nelle Ideas posibles (1692)», Studi Secenteschi, 51, 2010, pp. 153-197.

Nider, Valentina, «L'oratoria degli Incogniti in Spagna: le Declamaciones di Félix Lucio Espinosa y Malo e Antonio Lupis», en Gli Incogniti e l'Europa, ed. Davide Conrieri, Bologna, I libri di Emil, 2011, pp. 209-232.

Nider, Valentina, «Los clásicos desde el Siglo de Oro: de estatuas y cortesanas en los sonetos de Quevedo sobre Friné (Polimnia 78 y 79)», Criticón, 131, 2017, pp. 91-108. 
Olmos, Ricardo, «El amor del hombre con la estatua: de la Antigüedad a la Edad Media», en Kotinos. Festschrift für Erika Simon, ed. Heide Hilde Froning, Tonio Hölscher y Harald Mielsch, Mainz/Rhein, von Zabern, 1992, pp. 256-266.

Rosand, Ellen, Opera in Seventeenth-Century Venice: the Creation of a Genre, Berkeley, University of California Press, 1991.

Rubio Árquez, Marcial, y Sáez, Adrián J., La estirpe de Pigmalión: poesía y escultura en el Siglo de Oro, Madrid, Sial, 2017.

Ruiz Pérez, Pedro, «Para una caracterización del romance en el Bajo Barroco», Edad de Oro, 32, 2013, pp. 379-406.

Santa Croce, Antonio, La secretaria di Apollo, Venezia, Fra. Ma. Boccafranca, 1653.

Seco, Esperanza, «Historia de las traducciones literarias del italiano al español durante el Siglo de Oro (influencias)», Cuadernos para investigación de la literatura hispánica, 13, 1990, pp. 41-98.

Simone, Massimiliano, «Tra animato e inanimato. Figure di eroine nella Venezia Incognita», I/ Campiello, 1, 2016, s. p., disponible en <http://revues.univ-tlse2.fr/ ilcampiello/index. php?id=109>.

Stoichita, Victor I., Simulacros. El efecto Pigmalión: de Ovidio a Hitchcock, Madrid, Siruela, 2006.

van Gasel, Joris, II marmo spirante. Sculpture and Experience in Seventeenth-Century Rome, Berlin/Leiden, Akademie Verlag/Leiden University Press, 2013.

Vuelta García, Salomé, «La narrativa spagnola e l'Accademia degli Incogniti: Le traduzioni di Girolamo Brusoni», en Gli Incogniti e l'Europa, ed. Davide Conrieri, Bologna, I libri di Emil, 2011, pp. 277-314. 